\title{
Field survey on rice spikelet sterility in an extremely hot summer of 2018 in Japan
}

\author{
Mayumi Yoshimoto ${ }^{\mathrm{a} \uparrow}$, Hidemitsu SaKaI ${ }^{\mathrm{a}}$, Yasushi IshigooKa ${ }^{\mathrm{b}}$, Tsuneo Kuwagata ${ }^{\mathrm{a}}$, Tsutomu Ishimaru ${ }^{\mathrm{c}}$, \\ Hiroshi Nakagawa a , Atsushi Maruyama ${ }^{\mathrm{a}}$, Hitoshi Ogiwara ${ }^{\mathrm{d}, \mathrm{e}}$ and Kenji Nagata ${ }^{\mathrm{f}}$ \\ ${ }^{a}$ Institute for Agro-Environmental Sciences, NARO, 3-1-3 Kannondai, Tsukuba, Ibaraki 305-8604, Japan \\ ${ }^{\mathrm{b}}$ Hokkaido Agricultural Research Center, NARO, 9-4 Shinseiminami, Memuro, Kasai, Hokkaido 082-0081, Japan \\ ${ }^{\mathrm{c}}$ Central Region Agricultural Research Center, NARO, 1-2-1 Inada, Joetsu, Niigata 943-0193, Japan \\ ${ }^{\mathrm{d}}$ Institute of Crop Science, NARO, 2-1-2 Kannondai, Tsukuba, Ibaraki 305-8518, Japan \\ ${ }^{\mathrm{e}}$ Present address: NARO Headquarters, 3-1-1 Kannondai, Tsukuba, Ibaraki 305-8517, Japan \\ Western Region Agricultural Research Center, NARO, 6-12-1 Nishifukatsu-cho, Fukuyama-shi, Hiroshima 721-8514, Japan
}

\begin{abstract}
In rice (Oryza sativa L.), heat-induced spikelet sterility (HISS) has long been recognized a major threat in the production, and currently the potential risk of yield reduction is likely to be increasing under global warming. However, there have been few studies on HISS conducted under field conditions. In recent years in Japan, extremely high temperatures have frequently recorded in the daytime during the summer. In 2018, heat wave lasted from mid-July to late August, which overlapped the typical rice heading period from eastern to western Honshu and raised a concern about HISS during flowering. To examine this possibility, we surveyed rice sterility in eight prefectures in the Kanto, Tokai, and Kinki regions. During surveys in 2018 and 2019, we collected field data on the sterility of 'Koshihikari', the most popular rice variety in Japan, and the sterility ranged from 3.7 to $15.4 \%$ in paddy fields. The sterility tended to be higher in the paddy fields where heading occurred during the heat wave. We modeled the sterility rate using the heat dose based on daytime mean panicle temperature, with a threshold for HISS at $33^{\circ} \mathrm{C}$. The model estimates based on meteorological data showed that HISS can be induced even under current climatic conditions, depending on the timing of heading. Considering the projected global warming, this study raises an issue that rice plants would face a risk of HISS under the temperate climate in Japan.
\end{abstract}

Key words: Heat dose, Heat-induced spikelet sterility, Heat wave, Oryza sativa L., Panicle temperature

\section{Introduction}

Global warming and the resulting increased frequency of heat waves will likely reduce rice yields due to the effects of heat stress (Wassmann et al., 2009; Horie, 2019). One of the major concerns in heat stresses in rice is heat-induced spikelet sterility (HISS) at flowering. Satake and Yoshida (1978) showed that anthesis (flowering) is the most heat-sensitive process during the reproductive stage, since high temperatures at this time can lead to failure of grain setting. Previous studies using chamber experiments have shown that HISS begins when the daily maximum air temperature exceeds a certain threshold, such as $35^{\circ} \mathrm{C}$, and that a rapid decline in fertility occurs within 4 to $5^{\circ} \mathrm{C}$ above this threshold (Kim et al., 1996; Maruyama et al., 2013).

However, when the results of the chamber experiments were applied to open fields, the estimated sterility rate was much higher than the observed rate (Hasegawa et al., 2011). One main reason for this overestimation is the gap between the temperature of plant organs and the air temperature; this gap results from transpirational

Received; April 16, 2021

Accepted; August 4, 2021

†Corresponding author: yoshimot@affrc.go.jp

DOI: 10.2480 /agrmet.D-21-00024

(C) Author (s) 2021.

This is an open access article under the CC BY 4.0 license. cooling in paddy fields. Matsui et al. (2014) reported that the sterility rate was much lower than expected at extremely high temperatures, exceeding $40^{\circ} \mathrm{C}$, in a semi-arid Australian environment. The dry and windy climate stimulated transpirational cooling of the plant canopy, which reduced the panicle temperature by as much as $6^{\circ} \mathrm{C}$, resulting in stable pollination even under extremely hot conditions. On the other hand, Tian et al. (2010) reported that the panicle temperature can exceed the air temperature by $4^{\circ} \mathrm{C}$ in the Jianghan Basin, China, where the humid conditions and low wind speed reduced transpirational cooling of the plant canopy, resulting in high sterility despite a moderate daily maximum air temperature of approximately $35^{\circ} \mathrm{C}$. These cases showed the effectiveness of panicle temperature, but not air temperature, to predict HISS in paddy fields.

Previously, researchers have focused on quality deterioration as the effect of heat stress in Japanese rice, since the percentages of white immature grains (i.e., chalky rice) were increased by high temperatures during the ripening period (Mitsui et al., 2016). This deterioration has already become noticeable for farmers and researchers and was predicted by models that used appropriate temperature variables (e.g., Masutomi et al., 2015; Ishigooka et al., 2021). To mitigate this damage, adaptation measures are already taken, such as the development of heat-tolerant varieties and improved cultivation methods (Morita et al., 2016).

However, little research has been conducted on HISS in Japan because researchers have been confident that the problem is not apparent so far, and not serious under Japan's current climatic 
conditions. Hasegawa et al. (2011) conducted a pioneering survey of rice sterility in paddy fields in five prefectures in Japan during the record-breaking hot summer in 2007, when an unprecedented temperature of $40.9^{\circ} \mathrm{C}$ was recorded in mid-August in Kumagaya, Saitama Prefecture, in the Kanto region, and in Tajimi, Gifu Prefecture, in the Tokai region. Under such extremely high temperature conditions with heat wave (the temperature remained significantly higher than normal for a certain period), higher sterility rates were observed compared with the normal year, 2008. This indicated that HISS that had previously been observed in controlled environments, could also occur in Japanese paddy fields. The sterility rate was, however, smaller than that estimated from the daily maximum air temperature based on the findings of the chamber experiments. One explanation for this may be that the panicle temperature during flowering was lower than the daily maximum air temperature (Yoshimoto et al., 2011). In addition, on a regional or prefectural scale, flowering of many rice crops did not coincide with the heat wave, resulting in no obvious yield losses due to HISS. However, there has been no other research on the actual situation of HISS in paddy fields in Japan, and little data exists on sterility rates compared to the larger body of research on rice yield and quality collected annually during Japan's national Crop Survey. Therefore, there is considerable uncertainty in predicting HISS under present and future environments, and how it will affect yield remains to be studied. First of all, it is necessary to understand the actual status of HISS in the field and to identify its explanatory variables. Only when this knowledge allows us to quantify HISS in terms of environmental variables, will we be able to understand the process by which HISS influences yield.

In recent years, Japan has experienced frequent heat waves during the summer. In 2018, the summer was extremely hot, with temperatures occasionally surpassing the high temperature record in the 2007 survey, and the air temperature reached a record high of $41.1^{\circ} \mathrm{C}$ on July 23 in Kumagaya, Saitama Prefecture. In addition, the heat wave lasted from mid-July to late-August, which includes the typical rice heading period in eastern to western Honshu, which raised concerns about the possibility of HISS during flowering. To examine this possibility, we conducted a sterility survey in eight prefectures in the Kanto, Tokai, and Kinki regions that experienced high temperatures in 2018, according to the 2007 survey protocol. For comparison, we also conducted the same survey in 2019, which had more normal temperatures.

Our objectives were (1) to determine the occurrence of the HISS in 2018, an extremely hot year; (2) to determine the relationship between the sterility rate and thermal variables such as the air and panicle temperatures; and (3) to estimate the risk of HISS induction in 2018 and 2019 under the current climate conditions from meteorological data using the relationship determined in (2). Our ultimate goal is to estimate the impact on yield through HISS in the current and future climates. To achieve this goal, however, this study intended to first accumulate quantitative data of HISS, the actual status of which in paddy fields has not yet been clarified. This will reduce the uncertainty in yield impact assessment by determining the HISS using the appropriate environmental variables under current and future climatic conditions and contribute to the development of adaptation measures for HISS.

\section{Materials and Methods}

\subsection{Study sites}

We selected eight prefectures that had high temperatures in the summer of 2018 as our study sites (Table 1), and repeated the survey at the same sites in 2019. The study sites were in Ibaraki, Chiba, Gunma, and Saitama Prefectures in the Kanto region (in eastern Honshu), and in Gifu, Aichi, and Mie Prefectures in the Tokai region and Kyoto Prefecture in the Kinki region (in central and western Honshu). The study sites were mostly paddy

Table 1. Locations of the study sites.

\begin{tabular}{|c|c|c|c|c|c|c|c|}
\hline \multirow[t]{2}{*}{ Prefecture } & \multirow[t]{2}{*}{ Municipality } & \multirow[t]{2}{*}{ Location } & \multirow{2}{*}{$\begin{array}{l}\text { Latitude } \\
\left({ }^{\circ} \mathrm{N}\right)\end{array}$} & \multirow{2}{*}{$\begin{array}{l}\text { Longitude } \\
\quad\left({ }^{\circ} \mathrm{E}\right)\end{array}$} & \multirow{2}{*}{$\begin{array}{l}\text { Elevation } \\
\quad(\mathrm{m})\end{array}$} & \multicolumn{2}{|c|}{ Number of fields $(n)$} \\
\hline & & & & & & 2018 & 2019 \\
\hline \multicolumn{8}{|c|}{ Kanto region } \\
\hline Ibaraki & Mito city & Ibaraki Agricultural Center & 36.44 & 140.45 & 35 & $3(2)$ & $2(2)$ \\
\hline Ibaraki & Ryugasaki city & Ibaraki Agricultural Center & 35.89 & 140.21 & 5 & $3(2)$ & $3(2)$ \\
\hline Ibaraki & Tsukubamirai city & On-farm & 35.97 & 139.99 & 10 & $3(3)$ & $4(3)$ \\
\hline Chiba & Chiba city & $\begin{array}{l}\text { Chiba Prefectural Agriculture and Forestry } \\
\text { Research Center }\end{array}$ & 35.55 & 140.16 & 7 & $2(3)$ & $1(3)$ \\
\hline Chiba & Sanbu county, Yokoshibahikari town & On-farm & 35.70 & 140.48 & 5 & $1(3)$ & \\
\hline Gunma & Tatebayashi city & Gunma Agricultural Technology Center & 36.25 & 139.57 & 18 & $2(2)$ & $1(3)$ \\
\hline Gunma & Oura county, Itakura town & On-farm & 36.20 & 139.63 & 15 & $3(3)$ & $4(3)$ \\
\hline Saitama & Kumagaya city & $\begin{array}{l}\text { Saitama Prefectural Agriculture and Forestry } \\
\text { Research Center }\end{array}$ & 36.17 & 139.35 & 37 & $1(2)$ & $1(2)$ \\
\hline \multicolumn{8}{|c|}{ Tokai and Kinki regions } \\
\hline Gifu & Gifu city & Gifu Prefectural Agricultural Technology Center & 35.44 & 136.70 & 15 & $1\left(1^{*}\right)$ & $1(3)$ \\
\hline Gifu & Ibi county, Ono town & On-farm & 35.48 & 136.64 & 33 & $2\left(1^{*}\right)$ & \\
\hline Aichi & Nagakute city & Aichi Agricultural Research Center & 35.17 & 137.06 & 95 & $4\left(1^{*}\right)$ & $2(2)$ \\
\hline Mie & Iga city & Mie Prefecture Agricultural Research Institute & 34.71 & 136.14 & 158 & $3(3)$ & $3(2)$ \\
\hline Mie & Matsusaka city & Mie Prefecture Agricultural Research Institute & 34.64 & 136.50 & 6 & $4\left(1^{*}\right)$ & $1(2)$ \\
\hline Kyoto & Kameoka city & $\begin{array}{l}\text { Kyoto Prefectural Agriculture, Forestry and } \\
\text { Fisheries Technology Center }\end{array}$ & 35.01 & 135.56 & 102 & $1(2)$ & $2(2)$ \\
\hline
\end{tabular}

$n$ means the number of replicates of the paddy fields at the public experiment stations or the number of sampling areas from one paddy field in the farmlands. A superscripted * mark on the number $n$ indicates that samples were only obtained from one plot as replicate or area $(n=1)$ due to few paddy fields available for survey as we initiated the survey urgently in 2018 . 
fields at public experiment stations, but in some prefectures, we included farm paddy fields.

We selected 'Koshihikari', the most popular rice variety in Japan (Kobayashi et al., 2018), as the target variety for our study, and collected rice samples from paddy fields at the study sites. The basic cultivation information, such as the planting density; the amounts and timing of fertilizer application; and the dates of sowing, transplanting, and heading, were recorded in the paddy fields at the public experiment stations. We collected the same information for the farm paddy fields through interviews. The cropping season was almost typical for each prefecture, with sowing dates ranging from March 12 to May 11, transplanting dates from April 10 to June 1, and heading dates from July 11 to August 9. The amount of nitrogen $(\mathrm{N})$ fertilizer applied ranged from 4 to $10 \mathrm{~g} \mathrm{~m}^{-2}$ in paddy fields with basal application only. While in paddy fields where top-dressing was applied, the amounts of $\mathrm{N}$ fertilizer ranged from 2 to $6 \mathrm{~g} \mathrm{~m}^{-2}$ of basal application and from 0.85 to $5.2 \mathrm{~g} \mathrm{~m}^{-2}$ of top-dressing, with a total from 3.8 to $10.8 \mathrm{~g} \mathrm{~m}^{-2}$, and top-dressing was applied once or twice in the range of from 31 to 6 days before the respective heading date. Thus, all paddy fields were cultivated under conventional range of typical fertilizer, with no special cultivation conditions such as extremely low fertilizer application, which tended to increase the sterility rate (Hasegawa et al., 2011). Cultivation was done by pest control and water management conventional for each paddy field.

\subsection{Sampling and measurements}

We harvested five consecutive hills in the same row adjacent to the yield survey area in the paddy fields from two or more replicates at the public experiment stations. In the farm paddy fields, which were not experimental fields, three locations were set along a diagonal line of one paddy field as sampling areas representative of the paddy field as an alternative of replicates, from which we respectively harvested five consecutive hills in the same row that avoided the edge of the paddy field. The rice samples were air-dried and threshed. The spikelets were then water-screened and separated into submerged (fertile) spikelets and floating spikelets. After drying, the floating spikelets were soaked in an $80 \%$ ethanol solution to decolor the hull, after which the degree of ovary growth was examined by touch and by light penetration (Kobata et al., 2010). Spikelets that were totally empty and that had ovary growth less than half of the length of the spikelet were defined as sterile spikelets, and the floating spikelets that were not sterile were defined as stunted spikelets. We counted the number of spikelets in each category (sterile, stunted, and fertile) and calculated their percentages of the total number of spikelets.

\subsection{Meteorological data}

To get the overview of the two-year weather conditions of the eight target prefectures, we used weather data from the Japanese Weather Office or an AMeDAS station near the study sites. For detail analysis of the relationship between the sterility rate and weather conditions in each surveyed paddy field, the values of climate parameters were calculated using the $1-\mathrm{km}$ grid-point meteorology data developed by NIAES (Seino, 1993; Ishigooka et al., 2017) at the point nearest to the respective site. We focused on the daily maximum air temperature $\left(T_{\text {amax }}\right)$ and the daytime mean panicle temperature based on the 6-hour average from $09: 00$ to $15: 00\left(T_{\mathrm{pd}}\right)$ as explanatory variables for the sterility rate. Daily maximum air temperature has often been used as an explanatory variable for the sterility rate (e.g., Nakagawa et al., 2003; Hasegawa et al., 2011) because of the easy availability of data. The hourly panicle temperature was calculated using the heat balance model, IM ${ }^{2}$ PACT (Yoshimoto et al., 2011). Setting the actual flowering hours during the day at each study site as the time for calculating the average panicle temperature may provide the optimal explanatory variable for sterility rate. In this study, however, we chose the period from 09:00 to 15:00 for the averaging, which covers the entire flower opening time for 'Koshihikari' (Ishimaru et al. 2010).

The thermal variables were calculated by averaging $\left(T_{\operatorname{amax}}\right.$ and $T_{\mathrm{pd}}$ ) or by calculating the heat dose $(H D)$ over 5 days around the heading date according to the method of Hasegawa et al. (2011). We calculated $H D_{c}$ for temperatures above the threshold temperature $(c)$ based on the daytime mean panicle temperature $\left(T_{\mathrm{pd}}\right)$ as follows:

$$
H D_{c}=\sum_{i=a-2}^{a+2} \max \left(T_{i}-c, 0\right)
$$

where $T_{i}$ is the $T_{\mathrm{pd}}$ value on day $i$, and $a$ is the center date of the 5-day accumulation period.

\section{Results}

\subsection{Climate in 2018 and 2019}

Since August 16, 2007, when the record high temperature of $40.9^{\circ} \mathrm{C}$ was recorded at that time in Kumagaya, Saitama Prefecture and Tajimi, Gifu Prefecture, Japan has experienced hot summers and the record high temperature has been updated. In 2018, the record high temperatures were updated in many places, with $41.1^{\circ} \mathrm{C}$ recorded in Kumagaya, Saitama Prefecture on July 23 , and $41.0^{\circ} \mathrm{C}$ in Kanayama, Gifu Prefecture on August 6 and in Mino, Gifu Prefecture on August 8. In 2019, no location had recorded a high temperature reaching $41.0^{\circ} \mathrm{C}$. The frequent extreme high temperatures from July to August in 2018 overlapped the typical heading season for rice in Japan. Table 2 shows the climatic condition in the heading seasons of 2018 and 2019. The seasonal average daily mean air temperature was more than $2^{\circ} \mathrm{C}$ higher than normal in all eight prefectures of the study site, and up to $3.5^{\circ} \mathrm{C}$ higher in Gifu, Aichi, and Saitama Prefectures. In 2019, this temperature was slightly higher than normal, with a difference of 0.4 to $1.1^{\circ} \mathrm{C}$.

In 2018 , the seasonal average daily solar radiation was more than $3 \mathrm{MJ} \mathrm{m}^{-2} \mathrm{~d}^{-1}$ higher and the seasonal precipitation was much lower than normal in all eight prefectures (Table 2). In contrast, the solar radiation in 2019 was normal or slightly lower than normal in Tokai and Kinki regions, and the precipitation was higher than in 2018, especially in Gifu and Aichi Prefectures, where the difference was much larger. In summary, 2018 was a year of extremely high air temperature, with high radiation and low rainfall, whereas 2019 had a slightly warmer air temperature than normal, with normal radiation and higher rainfall than in 2018.

\subsection{Spikelet sterility in eight prefectures}

The measured sterile and stunted rates for the eight prefectures were plotted against the respective $50 \%$ heading dates along with 
Table 2. Seasonal means of daily mean air temperature, solar radiation, and seasonal precipitation in the heading seasons for 32 days from July 10 to August 10 in 2018 and 2019 at eight prefectures. Weather data were obtained from the Japanese Weather Office or an AMeDAS station near the study site. Normal values are averaged over the 30-year period from 1981 to 2010 .

\begin{tabular}{|c|c|c|c|c|c|c|c|c|c|c|}
\hline \multirow{2}{*}{\multicolumn{2}{|c|}{$\begin{array}{l}\text { Prefecture (name of Japanese } \\
\text { Weather Office/AMeDAS station } \\
\text { near the study site) }\end{array}$}} & \multicolumn{3}{|c|}{ Daily mean air temperature } & \multicolumn{3}{|c|}{$\begin{array}{l}\text { Solar radiation } \\
\left(\mathrm{MJ} \mathrm{m}^{-2} \mathrm{~d}^{-1}\right)\end{array}$} & \multicolumn{3}{|c|}{$\begin{array}{l}\text { Precipitation } \\
(\mathrm{mm})\end{array}$} \\
\hline & & (Normal) & 2018 & 2019 & (Normal) & 2018 & 2019 & (Normal) & 2018 & 2019 \\
\hline \multicolumn{11}{|c|}{ Kanto region } \\
\hline Ibaraki & (Tateno) & $(24.9)$ & 27.8 & 26.0 & $(16.2)$ & 20.4 & 17.3 & (124) & 110 & 120 \\
\hline Chiba & (Chiba) & $(26.1)$ & 28.6 & 26.6 & $(17.1)$ & 20.3 & 17.4 & (120) & 87 & 136 \\
\hline Gunma & (Tatebayashi) & $(26.4)$ & 29.5 & 27.1 & $(15.0)$ & 20.2 & 16.6 & (151) & 73 & 89 \\
\hline Saitama & (Kumagaya) & $(26.3)$ & 29.7 & 27.2 & $(16.0)$ & 20.7 & 16.6 & (163) & 73 & 121 \\
\hline \multicolumn{11}{|c|}{ Tokai and Kinki regions } \\
\hline Gifu & (Gifu) & $(27.5)$ & 31.1 & 28.1 & $(17.7)$ & 24.2 & 17.8 & (212) & 21 & 350 \\
\hline Aichi & (Nagoya) & $(27.3)$ & 30.8 & 27.7 & $(17.7)$ & 23.5 & 17.4 & (174) & 6 & 236 \\
\hline Mie & (Ueno) & $(26.1)$ & 28.8 & 26.9 & $(17.3)$ & 22.6 & 17.0 & (184) & 105 & 186 \\
\hline Kyoto & (Kyoto) & $(27.8)$ & 30.7 & 28.3 & (16.8) & 21.6 & 16.2 & (190) & 26 & 193 \\
\hline
\end{tabular}
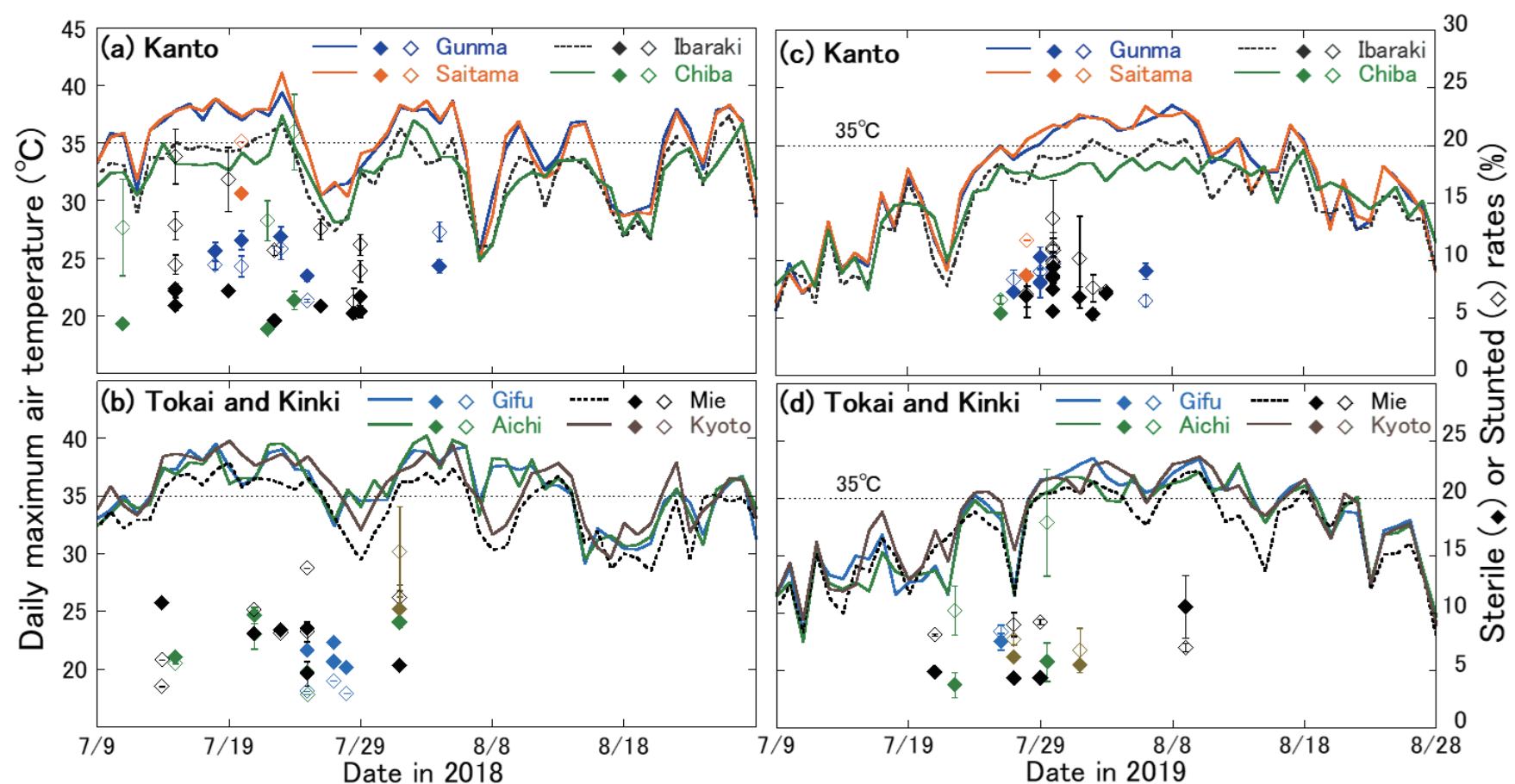

Fig. 1. Seasonal variation of daily maximum air temperature (lines) and the sterile or stunted rates (dots) plotted against the date of $50 \%$ heading in a paddy field in (a, b) 2018 and (c, d) 2019. The upper graphs (a, c) show data from the Kanto region and the lower graphs (b, d) show data from the Tokai and Kinki regions. Weather data were obtained from the Japanese Weather Office or an AMeDAS station near the study site. Values for the sterile and stunted rates are the mean $\pm \mathrm{SE}$ for each paddy field.

the daily maximum air temperature (Fig. 1). In 2018, the Kanto region experienced several heat waves in mid- to late July, early August, mid-August, and late August, with daily maximum air temperatures well above $35^{\circ} \mathrm{C}$ (Fig. 1a). The heat was especially severe in Gunma and Saitama. The Tokai and Kinki regions also experienced heat waves in mid- to late July and early August (Fig. 1b). The mean sterility rate (averaged over replicates) ranged from 3.7 to $15.4 \%$ in 2018 , with a particularly high sterility rate observed in paddy fields in the Kanto region, where panicles emerged around the time of the heat wave in late July.

In 2019, temperatures were low due to the long rainy season before late July, but high temperatures prevailed from late July to early August, with the daily maximum air temperatures exceeding $35^{\circ} \mathrm{C}$, especially in Gunma and Saitama in the Kanto region (Fig. 1c, d). The mean sterility rate ranged from 3.7 to $10.5 \%$ in 2019 , lower than in 2018, but tended to increase in paddy fields where panicles emerged during the high-temperature period.

The percentage of stunted spikelets in two-years (all eight prefectures combined) ranged from 2.8 to $20.8 \%$, with a mean value of $9.7 \% \pm 0.51 \%$ S.E. The stunted spikelets rate was significantly higher in paddy fields in the Kanto region in 2018 than others (ANOVA, $P<0.001$ ), and the high percentages of sterile and stunted spikelets sometimes reduced the fertility rate below $70 \%$. 


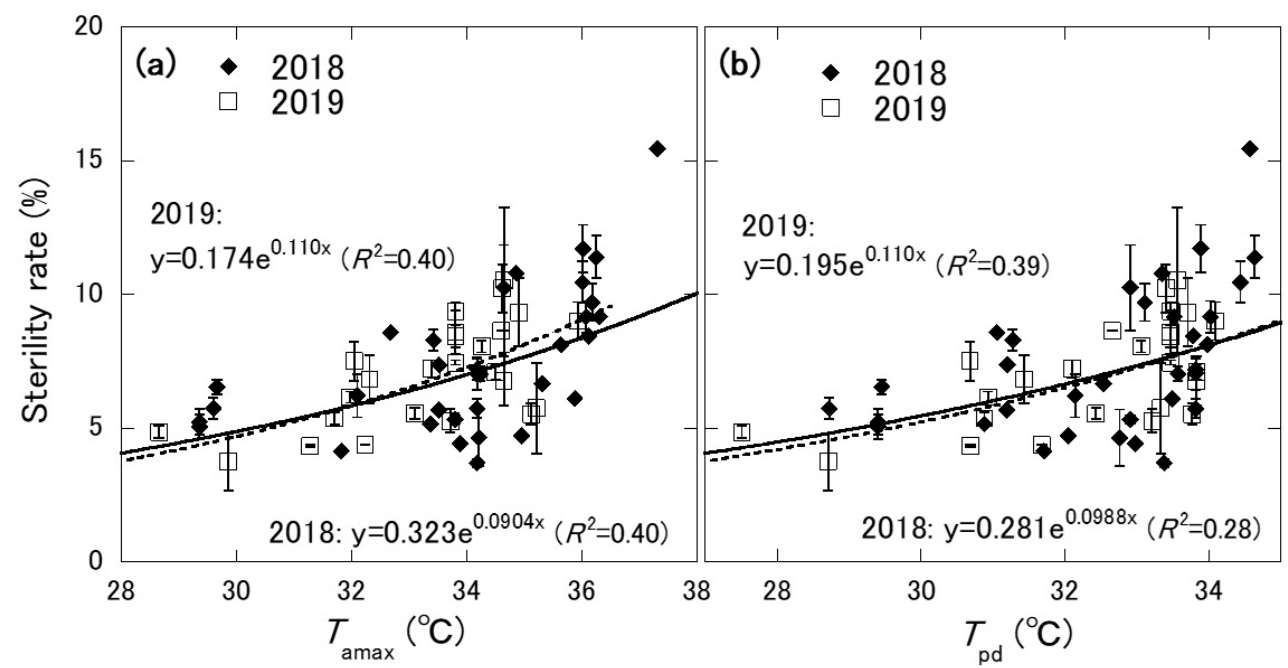

Fig. 2. Relationships between the sterility rate and the thermal variables (a) daily maximum air temperature $\left(T_{\text {amax }}\right)$ and (b) daytime 6-hour mean panicle temperature from 09:00 to 15:00 $\left(T_{\mathrm{pd}}\right)$. The thermal variables were averaged over a 5-day period centered on the $50 \%$ heading date. Thermal variables were calculated using the 1-km grid-point meteorology data developed by NIAES (Seino, 1993; Ishigooka et al., 2017) at the point nearest to each paddy field, and the hourly panicle temperature was calculated using the heat balance model, IM ${ }^{2}$ PACT (Yoshimoto et al., 2011). Values for the sterility rate are the mean \pm SE for each paddy field.

\subsection{Relationship between spikelet sterility and thermal variables}

We plotted the sterility rate against the thermal variables $\left(T_{\text {amax }}\right.$ and $\left.T_{\mathrm{pd}}\right)$ averaged over a 5-day period centered on the $50 \%$ heading date (Fig. 2). The sterility rate was significantly related to the average values of both $T_{\text {amax }}$ and $T_{\mathrm{pd}}$ over the 5 days of the heading period, but the difference in the response curves between years was slightly smaller when the $T_{\text {pd }}$ was used as the temperature index, where the response curves in 2018 and 2019 were consistent.

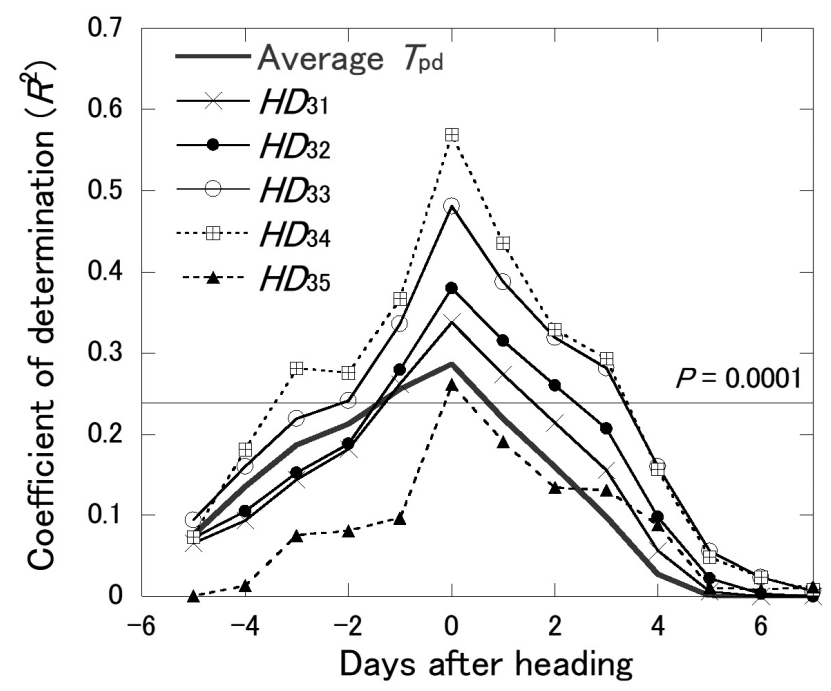

Fig. 3. Coefficient of determination $\left(R^{2}\right)$ for the linear relationship between the sterility rate and the daytime panicle temperature $\left(T_{\mathrm{pd}}\right)$ or the corresponding heat dose $(H D)$. The numbers in the $H D$ variable names represent the threshold temperature for $T_{\mathrm{pd}} . \mathrm{X}$-axis represents the center point of the 5-day period used to calculate the average temperature or $H D$ in days after heading. Data are from both years of 2018 and $2019(n=58)$. The horizontal solid line indicates the $R^{2}$ level above which the regression is significant at the $0.01 \%$ level.
Figure 3 shows the distribution of the coefficient of determination $\left(R^{2}\right)$ of the linear relationship between the sterility rate and the $T_{\mathrm{pd}}$ and the corresponding $H D$ relative to the center point of the 5-day period used to calculate $T_{\mathrm{pd}}$ or $H D$. The $R^{2}$ value peaked when the center of the 5-day period was set at the $50 \%$ heading date (days after heading $=0$ ). The peak value of $R^{2}$ was larger when using $H D$ based on $T_{\mathrm{pd}}$ than when using $T_{\mathrm{pd}}$ itself as the independent variable for linear regression, and it was the largest when the $H D$ threshold was about 33 to $34^{\circ} \mathrm{C}$. The peak value of $R^{2}$ was largest $(0.57)$ when the $H D$ threshold was $34^{\circ} \mathrm{C}$, but Figure $2 \mathrm{~b}$ shows that there were few cases when $T_{\mathrm{pd}}$ exceeded $34^{\circ} \mathrm{C}$. The number of non-zero $H D_{34}$ data was therefore greatly reduced, resulting in a larger $R^{2}$ value.

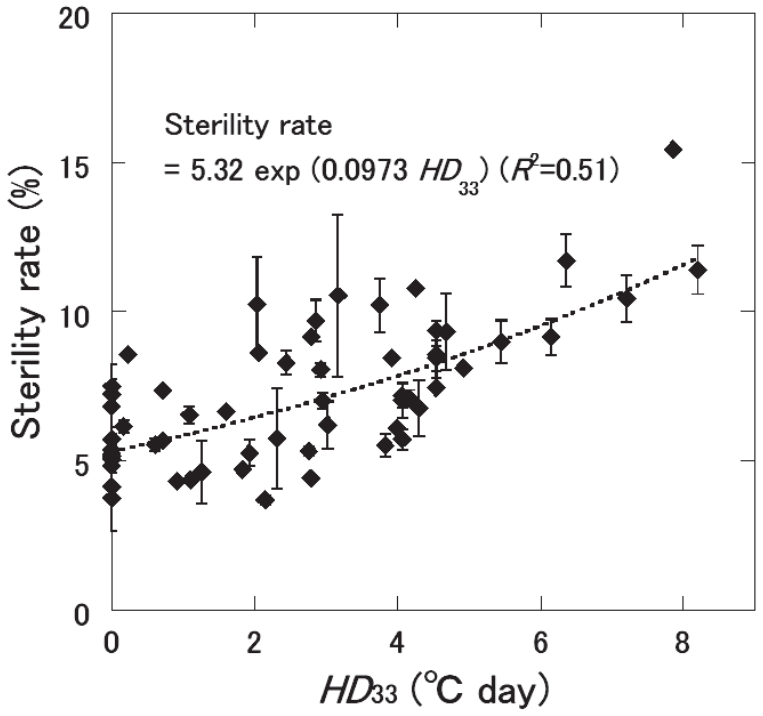

Fig. 4. Relationship between the sterility rate and the heat dose with a $33^{\circ} \mathrm{C}$ threshold $\left(H D_{33}\right)$ based on the daytime mean panicle temperature. Values for the sterility rate are the mean \pm SE for each paddy field. 
Therefore, we adopted the $H D$ value with a threshold of $33^{\circ} \mathrm{C}$ $\left(H D_{33}\right)$ as a more representative estimate, and used that value to investigate the relationship with the sterility rate (Fig. 4). The relationship between the sterility rate and $H D_{33}$ based on $T_{\text {pd }}$ was approximated by the following exponential equation:

$$
\text { Sterility rate }(\%)=5.32 \exp \left(0.0973 H D_{33}\right) \text {, }
$$

where the coefficient of determination $\left(R^{2}\right)$ was 0.51 .

\subsection{Distributions of possible spikelet sterility in the summers of 2018 and 2019}

We used equation 2 to estimate the distribution of possible spikelet sterility at the study sites in the summers of 2018 and 2019. Specifically, we assumed that each day from July 1 to September 10 represented a potential $50 \%$ heading date, and then calculated the $H D_{33}$ for the 5 days centered on each of those days to obtain the sterility rate using equation 2 . We classified the calculated sterility rates by season and region, and plotted their distributions as box-and-whisker plots (Fig. 5).

In 2018, sterility could most possibly occur in mid-July in all regions. In Kanto region and in the Tokai and Kinki regions, the median sterility rates were $6.6 \%$ and $9.0 \%$, respectively, and the maximum values were $12.7 \%$ and $15.5 \%$, respectively. In this survey, the number of samples from paddy fields that headed in mid-July in the Tokai and Kinki regions was smaller than in the Kanto region (Fig. 1b), and the maximum overall sterility rate was observed in mid-July in the Kanto region (15.4\%), but the risk of sterility would have been higher in the Tokai and Kinki regions than in the Kanto region if heading occurred during this period. Sterility could have been occurring in later periods as well. The sterility rate could reach a maximum of $11.7 \%$ and $10.3 \%$ in late July, and $10.7 \%$ and $9.5 \%$ in early August, in the Kanto region and in the Tokai and Kinki regions, respectively. In late August, the risk of sterility increased in the Kanto region, with a maximum value of $8.5 \%$.

In 2019, the likelihood of induced sterility was lower than in 2018, except in the Kanto region in early August, with a median sterility rate of $8.3 \%$ and a maximum value of $14.4 \%$, which were comparable to the predicted sterility under the heat wave in mid-July in 2018. In early August in 2019, the risk of sterility increased also in the Tokai and Kinki regions, with a maximum value of $9.0 \%$.

\section{Discussion}

'Koshihikari' is the most popular rice variety and is widely cultivated in Japan. It is moderately tolerant to HISS (Matsui et al., 2005). During our survey in 2018 and 2019, we were able to collect data on the sterility of 'Koshihikari', and sterility ranged from 3.7 to $15.4 \%$ in paddy fields under conventional cultivation practices with standard fertilizer application. Throughout both years, there was a tendency for higher sterility in paddy fields where the heading occurred during heat waves with a daily maximum air temperature exceeding $35^{\circ} \mathrm{C}$. This was consistent with the results of the 2007 survey (Hasegawa et al. 2011), although the degree of sterility induction cannot be directly compared with this earlier study because Hasegawa et al. (2011) survey included experimental paddies with different nitrogen treatments or varieties with different heat tolerance.

The thermal variables averaged over the 5 days of the heading

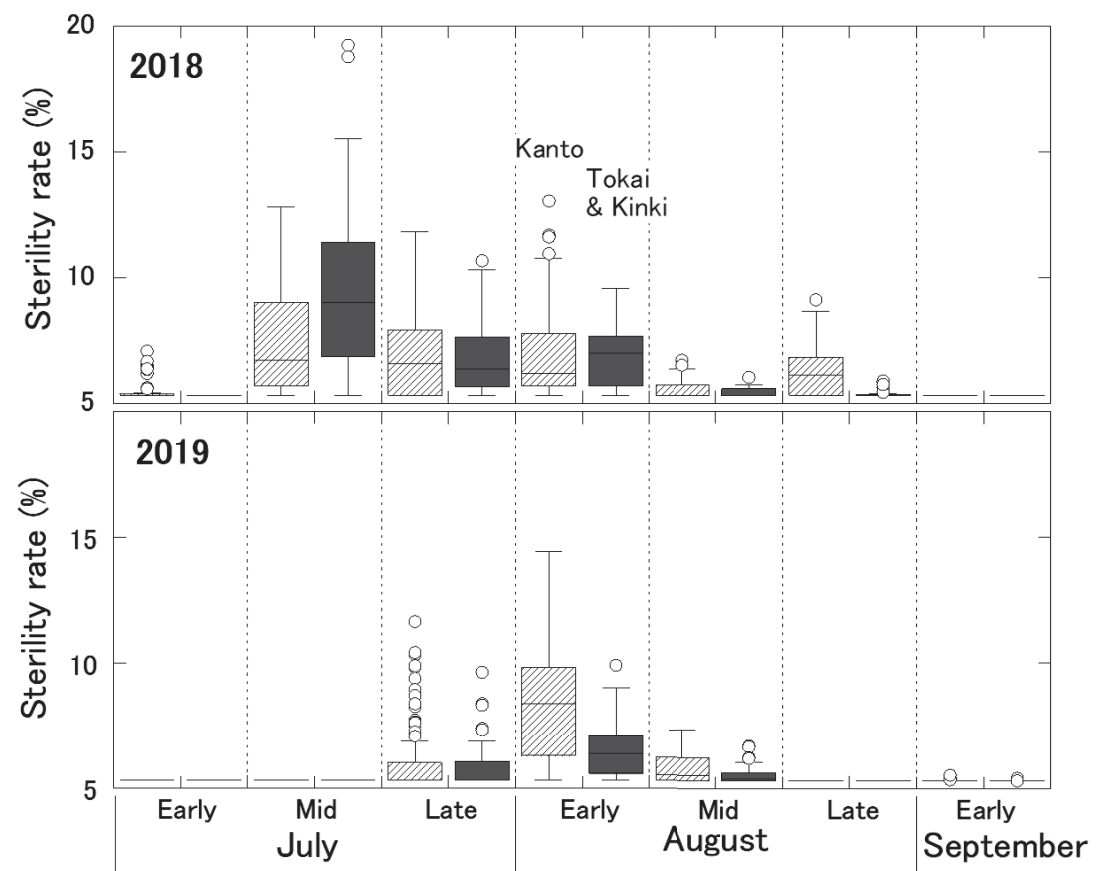

Fig. 5. Distributions of the possible sterility rate in Kanto region (stripe) and in Tokai and Kinki regions (black fill) in the summers of 2018 and 2019 , estimated by using equation 2 . The heat dose with a threshold temperature of $33^{\circ} \mathrm{C}\left(H D_{33}\right)$ was calculated for assumed 50\% heading dates between July 1 and September 10 at all the studied sites. The hourly panicle temperature was calculated by using the heat balance model, IM²PACT (Yoshimoto et al., 2011) using the 1-km grid-point meteorology data at the nearest point in the grid. Horizontal lines represent the medians, boxes represent the $25 \%$ to $75 \%$ interval, whiskers represent the $95 \%$ confidence interval, and any values outside of this range, outliers, are displayed by dots. 
period that all the surveyed paddy fields encountered ranged from 28.7 to $37.3^{\circ} \mathrm{C}$ for $T_{\text {amax }}$ and ranged from 27.5 to $34.6^{\circ} \mathrm{C}$ for $T_{\text {pd }}$ (Fig. 2). $T_{\text {pd }}$ was 0 to $3.1^{\circ} \mathrm{C}$ lower than $T_{\text {amax }}$, and the difference increased with increasing $T_{\text {amax }}$. On days with high $T_{\text {amax }}$, the relative humidity was lower, and this would have stimulated transpirational cooling of the plant canopy, resulting in a lower panicle temperature. This heat balance structure resembles that described by Matsui et al. (2014) in Australia, although the cooling effect in our study was not as extreme.

More of the paddy fields encountered higher temperatures in 2018 based on $T_{\text {amax }}$, where data for temperatures above $35^{\circ} \mathrm{C}$ accounted for $33 \%$ of the total data in 2018 , versus $12 \%$ (only three data points) in 2019 (Fig. 2a). However, the distribution of $T_{\text {pd }}$ was similar between the two years, with the maximum $T_{\mathrm{pd}}$ of $34.6^{\circ} \mathrm{C}$ in 2018 and $34.1^{\circ} \mathrm{C}$ in 2019 (Fig. 2b). This is because the difference between $T_{\text {amax }}$ and $T_{\text {pd }}$ tended to be smaller in 2019 due to the higher humidity in that year, whereas 2018 had high solar radiation and drier environmental conditions. By using $T_{\mathrm{pd}}$ instead of $T_{\text {amax }}$ as an index, the sterility model could be slightly improved, thereby obtaining a relationship with sterility rate that varied less between years.

In the present study, the threshold at which sterility started to be induced was about $33^{\circ} \mathrm{C}$ for both $T_{\text {amax }}$ and $T_{\text {pd }}$ (Fig. 2). In the Hasegawa et al. (2011) survey in paddy fields, the data for three japonica rice varieties, including 'Koshihikari', showed that the threshold was either $33^{\circ} \mathrm{C}$ or $34^{\circ} \mathrm{C}$ for $T_{\text {amax }}$. In the experiment by Maruyama et al. (2013) using temperature-gradient chambers, the threshold for 'Koshihikari' was about $35^{\circ} \mathrm{C}$ at the daily maximum air temperature, and was estimated to be about 33 to $34^{\circ} \mathrm{C}$ at the panicle temperature because it was observed 1 to $2^{\circ} \mathrm{C}$ lower than the air temperature in their environment. The present results are consistent with these findings on temperature thresholds.

Based on the relationship between the sterility rate and $H D_{33}$ (Fig. 4), the rate of increase in sterility above the threshold was about $7 \%$ per $8\left({ }^{\circ} \mathrm{C}\right.$-days $)$ increase in $H D_{33}$ based on the cumulative 5-day $H D$, which represents a mean increase of $4.4 \%$ per $1^{\circ} \mathrm{C}$ increase in $T_{\text {pd }}$. This rate is much smaller than previous findings from chamber experiments (e.g., $12 \%$ per $1{ }^{\circ} \mathrm{C}$ in Horie, $2019 ; 16 \%$ per $1{ }^{\circ} \mathrm{C}$ in Kim et al., $1996 ; 19 \%$ per $1^{\circ} \mathrm{C}$ in Maruyama et al., 2013). One reason for this, of course, is that the rate in a chamber experiment is evaluated based on the level of a single panicle, whereas in a paddy field, the community of panicles or plants has a temporal and spatial distribution of flowering, with different temperature exposures for each panicle during flowering. Although there are still few field-scale studies to support sterility modeling, Julia and Dingkuhn (2013) modeled sterility with the calculated panicle temperature based on data compiled for four cultivars at three sites with widely different climates, and found an increase of $7.6 \%$ per $1{ }^{\circ} \mathrm{C}$ elevation of panicle temperature. The increase rate of $4.4 \%$ per $1{ }^{\circ} \mathrm{C}$ in the present study is still smaller, but this may be because the sterility ranged up to $15 \%$ in the present study, and we only examined the onset of increasing sterility in a non-linear relationship. In addition, there are likely to be inter-varietal differences in the heat resilience.

Estimating the distribution of possible spikelet sterility with the model as a function of $H D_{33}$ based on panicle temperature (Fig. 5) suggests that even in 2019, with nearly normal climatic conditions, the sterility was comparable to that during the heat waves of 2018, when high temperatures occurred in early August in 2019. This suggests that HISS may be already occurring under current climatic conditions in temperate Japan, depending on the timing of heading, and that the risk will increase further with global warming.

The stunted spikelet rate tended to be higher in paddy fields where panicles headed in mid- to late July of 2018 in the Kanto region (Fig. 1a). Its overall average for all sites in 2018 and 2019 reached about $10 \%$, and together with the occurrence of sterility, the occurrence of stunted spikelets will further reduce the percentage of fertile grains that can be used for food, so elucidating and modeling the mechanism responsible for the stunting will be an important research challenge for the future. In addition, it has not been clarified yet how the increase in the sterility rate will affect yield. Rice yield is controlled by the sink size as the yield capacity and the source size as the amount of the photo assimilation product to be located to the sinks (e.g., Lubis et al., 2003). Under source-limited conditions, for instance, the failure of fertility due to HISS or other abiotic stresses may not be proportional to the reduction in yield because other factors become more important. Furthermore, the occurrence of sterility may influence on the source-sink balance, which leads to compensatory effects, such as changing the grain size distribution. It has been also reported that the late-emerging panicles can compensate for the failure to fertility of the early-emerging panicles, resulting in no reduction of the yield (e.g., Maruyama et al., 2015). Conversely, this means that even if HISS increases due to global warming and the resulting increasingly frequent heat waves, its effects on rice yield would not be directly detected by yield monitoring such as the monitoring that is done under Japan's national Crop Survey. In fact, according to the Japan's national Crop Survey, the rice crop index in the eight prefectures surveyed in this study was almost normal ranging from 97 to 102 in the extremely hot year of 2018, which was rather slightly higher than in the normal year of 2019 ranging from 95 to 98 . In the surveyed paddy field in Saitama Prefecture, where the highest sterility rate $(15.4 \%)$ was observed in this study in 2018, the spikelets number per unit area was $30 \%$ larger than normal because high temperatures in the early growing stage promoted tillering, but the yield was only $7 \%$ higher than normal (Saitama Prefectural Agriculture and Forestry Research Center, 2018). The reasons why the higher spikelets number per unit area did not proportionally lead the increase in yield could be due to HISS or lack of sources, and detailed identification of the factors is needed. Therefore, it is necessary to accumulate more detailed data on sterility through fertility surveys in paddy fields such as those in the present study, and to examine the relationship between sterility and yield components to support more accurate predictions of HISS and its effect on rice yield.

\section{Conclusion}

Our wide-area survey of paddy fields used to cultivate 'Koshihikari', the most popular variety of rice in Japan, revealed that HISS may be induced even under current climatic conditions in temperate Japan, depending on the timing of heading. Using the daytime mean panicle temperature as an index, it may be possible to estimate the risk of HISS under global warming, where the timing and intensity of the heat waves responsible for this damage will vary among years and among regions. On the other hand, we still do not 
know how HISS affects yield, and yield monitoring cannot detect the occurrence of HISS due to ongoing global warming. It will be necessary to carry out fertility surveys using samples collected from paddy fields to accumulate more detailed data on sterility and to examine the relationship between sterility and yield components. This knowledge will reduce the uncertainties in predicting HISS and will support the development of effective adaptation measures to mitigate the HISS associated with global warming.

\section{Acknowledgements}

We express our sincere thanks to all the public experiment stations and farmers who provided us with rice samples and the associated cultivation information. The research stations were the Ibaraki Agricultural Center, Chiba Prefectural Agriculture and Forestry Research Center, Gunma Agricultural Technology Center, Saitama Prefectural Agriculture and Forestry Research Center, Gifu Prefectural Agricultural Technology Center, Aichi Agricultural Research Center, Mie Prefecture Agricultural Research Institute, Kyoto Prefectural Agriculture and Forestry and Fisheries Technology Center. The farmers were in Tsukubamirai city in Ibaraki, Yokoshibahikari town in Chiba, Itakura town in Gunma, and Ono town in Gifu. Dr. Toshihiro Hasegawa of Institute for Agro-environmental Sciences, NARO gave us useful advice on the sampling and measurement methods in 2007 survey protocol. Dr. Satoshi Yoshinaga of the Central Region Agricultural Research Center, NARO, and Dr. Akira Miyata of the Institute for Agro-Environmental Sciences, NARO (belonged at the time of this survey) helped us to collaborate with public experiment stations in conducting the survey.

\section{References}

Hasegawa T, Ishimaru T, Kondo M et al., 2011: Spikelet sterility of rice observed in the record hot summer of 2007 and the factors associated with its variation. Journal of Agricultural Meteorology 67, 225-232.

Horie T, 2019: Global warming and rice production in Asia: Modeling, impact prediction and adaptation. Proceedings of Japan Academy, Series B 95, 211-245.

Ishigooka Y, Fukui S, Hasegawa T et al., 2017: Large-scale evaluation of the effects of adaptation to climate change by shifting transplanting date on rice production and quality in Japan. Journal of Agricultural Meteorology 73, 156-173.

Ishigooka Y, Hasegawa T, Kuwagata T et al., 2021: Revision of estimates of climate change impacts on rice yield and quality in Japan by considering the combined effects of temperature and $\mathrm{CO}_{2}$ concentration. Journal of Agricultural Meteorology 77, 139-149.

Ishimaru T, Hirabayashi H, Ida $\mathrm{M}$ et al., 2010: A genetic resource for early-morning flowering trait of wild rice Oryza officinalis to mitigate high-temperature-induced spikelet sterility at anthesis. Annals of Botany 106, 515-520.

Julia C, Dingkuhn M, 2013: Predicting temperature induced sterility of rice spikelets requires simulation of crop-generated microclimate. European Journal of Agronomy 49, 50-60.

Kim HY, Horie T, Nakagawa $\mathrm{H}$ et al., 1996: Effect of elevated $\mathrm{CO}_{2}$ and high temperature on growth and yield of rice. II. The effect on yield and its components of Akihikari rice. Japanese Journal of Crop Science 65, 644-651 (in Japanese with English abstract).
Kobata T, Akiyama Y, Kawaoka T, 2010: Convenient estimation of unfertilized grains in rice. Plant Production Science 13, 289-296.

Kobayashi A, Hori K, Yamamoto T et al., 2018: Koshihikari: a premium short-grain rice cultivar - its expansion and breeding in Japan. Rice 11, 15.

Lubis I, Shiraiwa T, Ohnishi M et al., 2003: Contribution of sink and source sizes to yield variation among rice cultivars. Plant Production Science 6, 119-125.

Maruyama A, Hamasaki T, Sameshima R et al., 2015: Panicle emergence pattern and grain yield of rice plants in response to high temperature stress. Journal of Agricultural Meteorology 71, 282-291.

Maruyama A, Weerakoon WMW, Wakiyama Y et al., 2013: Effects of increasing temperatures on spikelet fertility in different rice cultivars based on temperature gradient chamber experiments. Journal of Agronomy and Crop Science 199, 416-423.

Masutomi Y, Arakawa M, Minoda T et al., 2015: Critical air temperature and sensitivity of the incidence of chalky rice kernels for the rice cultivar "Sai-no-kagayaki". Agricultural and Forest Meteorology 203, 11-16.

Matsui T, Kobayasi K, Kagata $\mathrm{H}$ et al., 2005: Correlation between viability of pollination and length of basal dehiscence of the theca in rice under a hot-and-humid condition. Plant Production Science 8, 109-114.

Matsui T, Kobayasi K, Nakagawa $\mathrm{H}$ et al., 2014: Lower-than-expected floret sterility of rice under extremely hot conditions in a flooded-irrigated field in New South Wales, Australia. Plant Production Science 17, 245-252.

Mitsui T, Yamakawa H, Kobata T, 2016: Molecular physiological aspects of chalking mechanism in rice grains under high-temperature stress. Plant Production Science 19, 22-29.

Morita S, Wada H, Matsue U, 2016: Countermeasures for heat damage in rice grain quality under climate change, Plant Production Science 19, 1-11.

Nakagawa H, Horie T, Matsui T, 2003: Effects of climate change on rice production and adaptive technologies. In Rice Science: Innovations and Impacts for Livelihood (eds. Mew TW, Brar DS, Peng S, Dawe D, Hardy B). IRRI, Los Banos, 635-658.

Saitama Prefectural Agriculture and Forestry Research Center, 2018: Overview of the paddy rice crop in 2018 in Saitama Prefecture. https://www.pref.saitama.lg.jp/ documents/53276/2018suitosakugara.pdf (in Japanese)

Satake T, Yoshida S, 1978: High temperature-induced sterility in indica rices at flowering. Japanese Journal of Crop Science 47, 6-17.

Seino H, 1993: An estimation of distribution of meteorological elements using GIS and AMeDAS data. Journal of Agricultural Meteorology 48, 379-383 (in Japanese with English abstract).

Tian XH, Matsui T, Li S et al., 2010: Heat-induced floret sterility of hybrid rice (Oryza sativa L.) cultivars under humid and low wind conditions in the field of Jianghan Basin, China. Plant Production Science 13, 243-251.

Wassmann R, Jagadish SVK, Heuer S et al., 2009: Climate change affecting rice production: The physiological and agronomic basis for possible adaptation strategies. Advances in Agronomy 101, 59-122.

Yoshimoto M, Fukuoka M, Hasegawa T et al., 2011: Integrated micrometeorology model for panicle and canopy temperature (IM ${ }^{2} \mathrm{PACT}$ ) for rice heat stress studies under climate change. Journal of Agricultural Meteorology 67, 233-247. 